Article

\title{
Encapsulation of Babchi Oil in Cyclodextrin-Based Nanosponges: Physicochemical Characterization, Photodegradation, and In Vitro Cytotoxicity Studies
}

\author{
Sunil Kumar ${ }^{1}{ }^{(0)}$, Pooja ${ }^{2}$, Francesco Trotta $^{3}$ and Rekha Rao ${ }^{1, *}$ \\ 1 Department of Pharmaceutical Sciences, Guru Jambheshwar University of Science and Technology, \\ Hisar 125001, Haryana, India; sunilkundu450@gmail.com \\ 2 Department of Biotechnology, Indian Institute of Technology, Roorkee 247667, India; \\ poojasihag1592@gmail.com \\ 3 Department of Chemistry, University of Torino, 10135 Turino, Italy; francesco.trotta@unito.it \\ * Correspondence: rekhaline@gmail.com; Tel.: +91-999-104-8560
}

Received: 24 June 2018; Accepted: 20 August 2018; Published: 26 September 2018

\begin{abstract}
Babchi (Psoralea corylifolia) oil is an important essential oil used in several traditional medicines to cure various disorders. This phytotherapeutic agent possesses a number of pharmacological activities including antibacterial, antifungal, antioxidant, anti-inflammatory, immunomodulatory, and antitumor factors. However, volatile nature, poor stability, and solubility of babchi oil (BO) restrict its pharmaceutical applications. Therefore, the aim of the present work was to encapsulate this oil in $\beta$-cyclodextrin nanosponges (NS) in order to overcome the above limitations. To fabricate nanosponges, $\beta$-cyclodextrin was cross-linked with diphenyl carbonate in different molar ratios viz. 1:2, 1:4, 1:6, 1:8, and 1:10. The blank nanosponges were loaded with $\mathrm{BO}$ using the freeze-drying method. The particle size of the BO loaded nanosponges was found to lie between 200 and $500 \mathrm{~nm}$ with low polydispersity index. Furthermore, the zeta potential, the Fourier transform infrared spectroscopy, X-ray diffraction, thermal analysis, and electron microscopy were carried out for characterization of $\mathrm{BO}$ nanosponges. Results obtained from spectral analysis ascertained the formation of inclusion complexes. Additionally, solubilisation efficiency of $\mathrm{BO}$ was checked in distilled water and found enhanced by 4.95 times with optimized $\beta$-cyclodextrin nanosponges. The cytotoxicity study was carried out by the MTT assay using HaCaT cell lines. A significant improvement in photo-stability of essential oil was also observed by inclusion innanosponges. Lastly, the optimized formulation was tested for antibacterial activity using Staphylococcus aureus, Pseudomonas aeruginosa, and Escherichia coli. Therefore, encapsulation of BO in nanosponges resulted in efficacious carrier system in terms of solubility, photo-stability, and safety of this oil along with handling benefits.
\end{abstract}

Keywords: essential oil; Psoralea corylifolia; cytotoxicity; encapsulation; solubilisation

\section{Introduction}

Encapsulation strategies play a vital role for the delivery of poorly soluble, unstable, or toxic moieties. Enhancing their encapsulation efficiency using carrier systems can help achieve better therapeutic efficacy due to a reduction in side effects. Therefore, newer encapsulation techniques are explored using natural polymers nowadays.

Naturally occurring polysaccharides act as attractive polymers for drug delivery systems due to their high biodegradability, biocompatibility, and lower cost [1]. One of the most extensively used natural polysaccharide includes cyclodextrins. Cyclodextrins possess the ability to encapsulate guest 
molecules inside their internal cavity, which leads to modification of the physico-chemical features of the host molecules like the physical state, solubility, stability, and bioavailability [2,3]. However, cyclodextrins are unable to form inclusion complexes with hydrophilic or high-molecular-weight molecules [4]. In the last few years, a nanosponge has been proposed as an advanced drug delivery system involving the reaction of cyclodextrin with a suitable cross-linking agent for encapsulation of difficult-to-formulate moieties [5-8]. These are hyper cross-linked nanoporous structures reported to form inclusion and non-inclusion complexes with a variety of drugs to enhance their solubility, stability, permeability, cytotoxicity, and other such drug delivery features [9].

Essential oils composed of lipophilic and highly volatile secondary plant metabolites represent a "natural" alternative in pharmaceutical, cosmetic, food, and agriculture fields due to their antiviral, antimicrobial, antifungal, insecticidal, nematicidal, and antioxidant properties [10]. An important essential oil obtained from Psoralea coryfolia(belonging to family Fabaceae) is babchi oil (BO), which is a vital phytotherapeutic agent reported for the treatment of psoriasis [11]. An anti-psoriatic effect of BO is attributed to psoralen, bakuchiol, and isopsoralen content, which are the major constituents of this oil [11,12]. These chief constituents (furocoumarins) collectively inhibit DNA synthesis, which causesa reduction in cell proliferation [13]. In addition, the $\mathrm{BO}$ also possesses numerous activities like antifungal, antibacterial, antiviral, antitumor, cytotoxic, antioxidant, antidepressant and stimulant [11]. However, this essential oil is found to have poor aqueous solubility, stability, and is volatile in nature [14]. These drawbacks limit the practical use of this oil in spite of its numerous beneficial effects. Faiyazuddin et al. fabricated and evaluated solid lipid nanoparticles of BO. However, poor stability, sterilization difficulties, and low drug loading limits the use of solid lipid nanoparticles [15]. Unlike these, cyclodextrin nanosponges possess larger cavities for host molecules to be entrapped in the nano pores due to a crosslinking network of a polymer and a cross linker. In addition, these nano systems have also been proposed as stable carriers for the entrapment of a variety of therapeutic agents [16-19]. However, various phyto-constituents like resveratrol [20], $\gamma$-oryzanol [18], curcumin [21], quercetin [19], rutin, phloridzin, and chlorogenic acid [22] have been successfully encapsulated in cyclodextrin nanosponges.There are no reports on the encapsulation of essential oils using cyclodextrin nanosponges. Based on the facts above, the purpose of the present study was to evaluate the nanosponge as an encapsulating agent for babchi essential oil found in Psoralea coryfolia seeds. In this preliminary investigation, $\beta$-cyclodextrin $(\beta-C D)$ nanosponges were purposely tailored for the formulation of this essential oil with poor water solubility. Prepared nanosponges may solubilize $\mathrm{BO}$ by complexation and improve its stability. The physico-chemical characterization of the $\mathrm{BO}$ nanosponge formulations was carried out by thermogravimetry analysis (TGA), X-ray powder diffraction (XRPD), and Fourier transform infra-red (FTIR) spectroscopy. The fabricated nanosponges (NS) were also characterized regarding topography and a microstructure using a field emission scanning electron microscopy (FE-SEM) and transmission electron microscopy (TEM). In addition, particle size analysis, zeta potential, and a polydispersity index were also investigated for $\mathrm{BO}$ loaded nano-formulations. The safety of the optimized nanosponges was assessed with an MTT assay using HaCaT (human epidermal keratinocyte) cell line. Furthermore, in vitro antibacterial studies were explored to compare the antibacterial efficacy of the optimized nanosponges against plain $\mathrm{BO}$. The photo-degradation of $\mathrm{BO}$ and $\mathrm{BO}$ loaded nanosponges upon UVA irradiation were also carried out.

\section{Materials and Methods}

\subsection{Materials}

The BO was obtained as a generous gift sample from Pukhraj Herbals (Mandsaur, India). $\beta$-cyclodextrin ( $\beta-C D)$ was procured from JayChemMarketing (Mumbai, India). Diphenyl carbonate (DPC) was purchased from Sigma-Aldrich (Milan, Italy). All other reagents and chemicals used were of an analytical grade. Double distilled water was used throughout the studies. 


\subsection{Gas Chromatography Mass Spectrometry of the Babchi Oil (BO)}

Gas chromatography mass spectrometry (GC-MS) analysis was carried out using a GC-2010 gas chromatography (Shimadzu Corp., Kyoto, Japan) equipped with a GCMS-QP2010 Plus along with thermal desorption system TD 20 (Shimadzu Corp., Kyoto, Japan). A sample ( $0.2 \mu \mathrm{L})$ was injected into the split injector with a split ratio of $1: 100$. The oven temperature was kept at $50{ }^{\circ} \mathrm{C}$ for $2 \mathrm{~min}$, increased to $210^{\circ} \mathrm{C}$ at a rate of $3{ }^{\circ} \mathrm{C} / \mathrm{min}$ and held for $1 \mathrm{~min}$, and then increased to $280^{\circ} \mathrm{C}$ at a rate of $8{ }^{\circ} \mathrm{C} / \mathrm{min}$ and held for $6 \mathrm{~min}$. The injector temperature was $260^{\circ} \mathrm{C}$ while the ion source temperature and interface temperature were $230^{\circ} \mathrm{C}$ and $270{ }^{\circ} \mathrm{C}$, respectively. The identification of constituents was established in comparison of their mass spectra. The peak area measurement (expressed in an area percentage) was used for quantitative analysis of each component of $\mathrm{BO}$.

\subsection{Synthesis of Nanosponges}

Cyclodextrin-based nanosponges were prepared using a previously reported procedure $[23,24]$. Different molar ratios of $\beta-C D$ and DPC $(1: 2,1: 4,1: 6,1: 8$, and 1:10) were used for the preparation of BO nano-carriers.

Finely homogenized anhydrous $\beta$-CD and DPC were gradually heated from 90 to $100{ }^{\circ} \mathrm{C}$ under magnetic stirring for $6 \mathrm{~h}$. Then, crystals of phenol formed at the neck of the flask were carefully removed. The reaction mixture was allowed to cool at room temperature. The solid obtained was repeatedly washed with double distilled water in order to remove unreacted $\beta-C D$ and subsequently purified by a soxhlet extraction process using acetone to separate the unreacted DPC and phenol from the product. After every washing of acetone, a test for phenol was performed using ferric chloride solution. The nanosponges were dried at $40{ }^{\circ} \mathrm{C}$ in a hot air oven for $2 \mathrm{~h}$ and stored at room temperature in a dessicator until further use [24].

\subsection{Solubilization Efficiency of Nanosponges}

In order to examine the solubilization enhancement capacity, the solubilization efficiency of the BO in $\beta-C D$ and all the batches of nanosponges (NS2, NS4, NS6, NS8, and NS10) were investigated [19,21]. An excess amount of the BO $(50 \mathrm{mg})$ was taken with a fixed amount $(20 \mathrm{mg})$ of blank nanosponges in $20 \mathrm{~mL}$ of double distilled water in a volumetric flask. The volumetric flasks were allowed to shake on a mechanical shaker at an ambient temperature for $24 \mathrm{~h}$. After equilibrium, the obtained suspensions were centrifuged at 10,000 rpm for $10 \mathrm{~min}$ to assort a colloidal supernatant and free BO. Dimethyl sulfoxide $(10 \mathrm{~mL})$ was added to supernatants in order to extract the encapsulated $\mathrm{BO}$ from the nanosponges. After $2 \mathrm{~h}$, the colloidal supernatant solutions were examined by a UV spectrophotometer (Varian Cary-5000, Christ, The Netherlands) at $265 \mathrm{~nm}$ using a calibration curve of $\mathrm{BO}$. The experiments were performed in triplicate.

\subsection{Preparation of Babchi Oil-Loaded $\beta$-Cyclodextrin Nanosponges}

BO was loaded in the blank nanosponges by using a freeze-drying technique, which was previously reported [25]. Accurately weighed quantities (1 gm) of blank nanosponges were dispersed in $50 \mathrm{~mL}$ of double distilled water using a magnetic stirrer, then an excess amount of BO was added, and the mixture was sonicated for $10 \mathrm{~min}$ and kept for $24 \mathrm{~h}$ under stirring. The suspensions were centrifuged at $3000 \mathrm{rpm}$ for $10 \mathrm{~min}$ to separate the un-complexed $\mathrm{BO}$ as a residue below the colloidal supernatant. The supernatant obtained was freeze-dried using a lyophilizer (Alpha 2-4 LD Plus CHRIST, Osterode, Germany) at $-81^{\circ} \mathrm{C}$ temperature and operating pressure of $0.0010 \mathrm{mbar}$. The dried powder was stored in a desiccator. BO-loaded NS formulations obtained were named asBONS2, BONS4, BONS6, BONS8, and BONS10 depending on the ratio of $\beta-C D$ and DPC used in the fabrication of nanosponges [19]. 


\subsection{Evaluation of Nanosponges}

\subsubsection{Determination of the BO Content in the Nanosponges}

A weighed amount of all types of BO-loaded NSs was dispersed in dimethylsulfoxide (DMSO), sonicated for 10 min to break the nanosponge complex, and diluted using DMSO. Furthermore, the prepared samples were analysed by using a UV spectrophotometer at $265 \mathrm{~nm}$ to ascertain the BO content in nanosponges. The encapsulation efficiency and essential oil loading capacity were calculated using the following equations.

$$
\begin{gathered}
\text { Babchi oil loading }(\%)=\frac{\text { weight of essential oil in nanosponges }}{\text { weight of nanosponges }} \times 100 \\
\text { Entrapment efficiency }(\%)=\frac{\text { weight of essentail oil in nanosponges }}{\text { weight of essential oil feed initially }} \times 100
\end{gathered}
$$

\subsubsection{Determination of Size, Polydispersity Index, and Zeta Potential of the Nanosponges}

The size and polydispersity indices of the all NSs were determined by using dynamic light scattering with a Malvern Zetasizer (Malvern Instruments Ltd., Worcestershire, UK). The samples were suitably diluted with filtered double distilled water before each measurement. Zeta potential measurements were made using an additional electrode in the same instrument. For the zeta potential determination, the instrument was operated at a constant temperature of $25^{\circ} \mathrm{C}$ using a clear disposable zeta cell. Twelve measurements were carried out and their average was expressed.

Based on the results of the encapsulation and solubilisation efficiency, the formulation BONS4 was selected for further FTIR, TGA, XRPD, FE-SEM, and TEM.

\subsubsection{Fourier Transform Infrared Spectroscopy}

Fourier transform infrared spectra were recorded in the spectral range from 4000 to $650 \mathrm{~cm}^{-1}$ using a Perkin Elmer Spectrum (Waltham, MA, USA), BX II instrument in the attenuated total reflectance (ATR) mode with a diamond crystal using 45 scans per spectrum and a resolution of $2 \mathrm{~cm}^{-1}$.

\subsubsection{Thermal Analysis}

Thermal analysis was performed using EXSTAR TG/DTA 6300 (Thermo gravimetric/Differential Thermal Analyzer (TG/DTA) (SII 6300 EXSTAR, Tokyo, Japan)). A heating rate of $10^{\circ} \mathrm{C} / \mathrm{min}$ was employed in a temperature range from 5 to $500{ }^{\circ} \mathrm{C}$. The standard aluminium pans were used. Alumina powder was used as reference standard. About $10 \mathrm{mg}$ of the sample was placed on the aluminium pan and subjected to the above mentioned program under a nitrogen atmosphere with $200 \mathrm{~mL} / \mathrm{min}$ speed. Thermal analysis was performed to understand inclusion of $\mathrm{BO}$ in nanosponges. The experiments were carried out in triplicate.

\subsubsection{X-ray Powder Diffraction}

In order to explore the host-guest interaction and structure of the resulting nanocomplexes, an X-ray powder diffraction study was carried out. Plain $\beta-C D$, blank nanosponges, and BO loaded nanosponges were subjected to XRPD using a Powder X-ray Diffractometer (Bruker D8 Advance, Karlsruhe, Germany). Diffraction profiles were analysed at a $2 \theta$ of $10^{\circ}$ to $80^{\circ}$ sequential collection. The step time was $0.5 \mathrm{~s}$ and the time of acquisition was $1 \mathrm{~h}$.

\subsubsection{Surface Morphology}

Field Emission Scanning Electron Microscopy

The morphology of the nanosponges and BO-loaded nanosponges was observed under FE-SEM (Carl Zeiss UltraPlus, Oberkochen, Germany). The samples were sprinkled on a double-sided carbon 
adhesive tape stuck to an aluminium stub and then metallized with a thin film (10 $\AA$ ) of gold under an argon atmosphere for $90 \mathrm{~s}$ to minimize the charging effects.

Transmission Electron Microscopy

The morphology of the blank nanosponges and BONS4 was also observed under TEM (FEI Tecnai $\mathrm{G}^{2} 20$ S-Twin, Hillsboro, OR, USA). One drop of formulation suspension was deposited on a carbon-coated copper grid and allowed to dry for contrast enhancement.

\subsection{Cytotoxicity Studies Against the HaCaT Cell Line}

The cytotoxicity of the BO and BONS4 were assessed using HaCaT cell lines. The HaCaT is a spontaneously transformed aneuploid immortal keratinocyte cell line from adult human skin [26]. These cell lines are used due to the high tendency to differentiate and anti-proliferate in vitro [27].

For cytotoxicity studies, the samples were accurately weighed and mixed to obtain the desired concentration. The mixture was dissolved in distilled DMSO and volume was made up with Dulbecco's Modified Eagle's medium (DMEM) and supplemented with 2\% inactivated Fetal Bovine Serum (FBS) in order to obtain a stock solution $(1 \mathrm{mg} / \mathrm{mL})$. After sterilization of the stock solution by filtration, $0 \mu \mathrm{g} / \mathrm{mL}$ to $320 \mu \mathrm{g} / \mathrm{mL}$ concentration aliquots were prepared from stock solution for carrying out cytotoxic analysis.

HaCaT cells were cultured in DMEM medium and supplemented with $10 \%$ inactivated FBS, penicillin $(100 \mathrm{IU} / \mathrm{mL})$, and streptomycin $(100 \mu \mathrm{g} / \mathrm{mL})$ in a humidified atmosphere of $5 \% \mathrm{CO}_{2}$ at $37^{\circ} \mathrm{C}$ until confluent. The cells were dissociated with a TPVG solution $(0.2 \%$ trypsin, $0.02 \%$ EDTA, $0.05 \%$ glucose in PBS).Furthermore, 50,000 cells/well of cells were seeded in a 96-well plate and incubated for $24 \mathrm{~h}$ at $37^{\circ} \mathrm{C}, 5 \% \mathrm{CO}_{2}$ incubator.

The monolayer cell culture was trypsinized and the cell count was adjusted to $1.0 \times 10^{5}$ cells $/ \mathrm{mL}$ using respective media containing 10\% FBS. To each well (96 well microtiter plate), $100 \mu \mathrm{L}$ of the diluted cell suspension (50,000 cells/well) was added. The plates were then incubated at $37^{\circ} \mathrm{C}$ for $24 \mathrm{~h}$ in a $5 \% \mathrm{CO}_{2}$ atmosphere. After an incubation period, 3-[4-dimethylthiazol-2-yl]-2, 5-diphenyl tetrazolium bromide (MTT) $(5 \mathrm{mg} / 10 \mathrm{~mL}$ of MTT in PBS) was added to each well. After incubation of $4 \mathrm{~h}$ at $37^{\circ} \mathrm{C}$ in a $5 \% \mathrm{CO}_{2}$ atmosphere, the supernatant was removed. $100 \mu \mathrm{L}$ of DMSO was added to the collected supernatant. The plates were read at $590 \mathrm{~nm}$ with a microplate reader (model 450). The percentage growth inhibition was determined and the concentration of the test drug needed to inhibit cell growth by 50\% (IC50 values) was generated from the dose-response curves.

\subsection{Photodegradation Study}

The photo degradation of BO and BONS4 was carried out under a UV lamp (Philips 40 W TL K05, Gurgaon, India). Both samples were placed at a 10-cm distance from the UV lamp for $60 \mathrm{~min}$ a dark environment. The samples were exposed to a UVA wavelength range from 320 to $400 \mathrm{~nm}$ at room temperature $\left(25 \pm 2^{\circ} \mathrm{C}\right)$. The samples were collected at time intervals of 10 minutes and quantitatively analyzed using a UV spectrophotometer (Varian Cary 5000, Christ, The Netherlands). The experiment was performed in triplicate.

\subsection{Antibacterial Activity}

The antibacterial activity of the $\mathrm{BO}$, blank nanosponges, and $\mathrm{BO}$ loaded nanosponges was evaluated by an agar well diffusion method using nutrient agar medium. Nutrient agar medium $(30 \mathrm{~mL})$ was poured into each petri plate. The test bacteria i.e., Staphylococcus aureus ATCC 25923 (S. aureus), Pseudomonas aeruginosa ATCC 27853 (P. aeruginosa), and Escherichia coli ATCC 25922 (E. coli) $\left(1 \times 10^{6} \mathrm{CFU} / \mathrm{mL}\right)$ were inoculated onto the surface of medium with a sterile spreader. Afterwards, the agar medium is punched using a cork borer (diameter $6 \mathrm{~mm}$ ). BO loaded nanosponges (equivalent to $50 \mathrm{mg}$ of BO) were pipetted into the wells. The antibiotic streptomycin (STP) $(10 \mu \mathrm{g} / \mathrm{mL})$ was used as a positive control. The plates were allowed to incubate at $37^{\circ} \mathrm{C}$ for $24 \mathrm{~h}$. The diameter of 
the growth inhibition of all the samples surrounding the wells was examined after the incubation period. The experiment was repeated thrice and the antibacterial activity was calculated as an average value [28].

\subsection{Statistical Analysis}

All the experiments were performed in triplicate and the results were reported as mean \pm standard deviation. Statistical measurements were carried out by using the GraphPad Prism version 5.01 software (GraphPad Software, San Diego, CA, USA). A One-way ANOVA (non-parametric) Kruskalwallis test was used to appraise the significant difference between the results.

\section{Results and Discussion}

Numerous efforts have been devoted to the method of the preparation and the application of nanosponges over the last decade. Amongthe various types of nanosponges, cyclodextrin-based nanosponges have received more attention and are widely studied [17].

Cyclodextrins are biodegradable, versatile compounds used to improve physicochemical and pharmaceutical properties such as solubility, stability, and bioavailability of administered drug molecules reported in literature [29]. Among the natural $(\alpha, \beta, \gamma)$ cyclodextrins, $\beta$-cyclodextrin has the highest complexing ability and stability with cross-linking agents. In addition, cavity dimensions, the low cost of production, and higher productive rates are other advantages offered by cyclodextrins for nanosponge preparation [30]. Various crosslinking agents like carbonyl diimmidazole, hexamethylenediisocynate, toluelyldianhydride, diisocynate, or carbonate and diphenyl carbonate have been explored in literature for nanosponge formulations [6]. In the present work, diphenyl carbonate was chosen as a cross-linker owing to its trifling acute dermal toxicity ( $2000 \mathrm{mg} / \mathrm{kg}$ ), no skin irritancy, sensitization, and minimum lineal photo-degradation [31].

Nanosponges can be crafted using various techniques such as an ultrasound-assisted synthesis [25], a solvent evaporation technique [21], an emulsion solvent diffusion method [32], microwave assisted synthesis [33], normal solution synthesis [34], and a melt method [24].

In the present study, the melt technique has been used for preparing BO cyclodextrin nanosponges. The advantage of using this technique is that it results in a crystalline product without the use of organic solvents. Furthermore, it has been revealed that the drug loading is greater in crystalline nanosponges in comparison to paracrystalline ones [35].

Aldawsari et al. formulated and evaluated lemongrass oil-loaded ethylcellulose nanosponges using an emulsion solvent evaporation technique [36]. However, cyclodextrin nanosponges have not been explored for encapsulating essential oils. Yet these may prove as promising nanocarriers for these bioactives. Drug loading in cyclodextrin nanosponges is usually done at room temperature with afreeze drying technique after the fabrication of blank nanosponges. Hence, these nanocarriers may prove beneficial for essential oils, which are generally thermolabile, volatile, and poorly soluble. Thus, taking this into consideration, cyclodextrin nanosponges have been explored for the encapsulation of $\mathrm{BO}$ in the present investigation.

\subsection{Identification of Various Compounds in BO Using GC-MS}

Generally, gas chromatography is applied for qualitative analysis while for quantitative estimation, it is coupled with mass spectrometry. In the present work, GC-MS was used to identify the volatile components present in the $\mathrm{BO}$ sample. A large number of constituents were detected in this essential oil. Among them, bakuchiol (4-(3,7-Dimethyl-3-vinylocta-1,6-dien-1-yl)phenol) was seen as a major component with the highest percentage area $(65.37 \%)$. Other main constituents included $2 \mathrm{H}$-furo[2 $\mathrm{H}]$-1-benzopyran-2-one (2.59\%), caryophyllene oxide $(2.11 \%)$, oleoyl chloride (1.70\%), 2-Phenyl-4-anilino-6[1H]-pyrimidinone (1.47\%), 9-Octadecenoic acid (1.29\%), 2-[5-(2Methyl-benzooxazol-7-yl)-1H-pyrazol-3-yl]-phenol (1.11\%), andstigmast-5-en-3-ol (1.04\%). The rest of 
the volatile constituents were found at concentrations lower than $1 \%$ (caryophyllene, hexadecanoate, 2H-furo[2H]-1-benzopyran-2-one, solanesol, and stigmasterol).

\subsection{Nanosponge Fabrication}

In the present study, the blank nanosponges were fabricated by using a melt method in five different molar concentrations (Table 1) using $\beta-C D$ and DPC and their physico-chemical characterization was performed.

Table 1. Molar ratios of $\beta$-cyclodextrin and diphenyl carbonate $(n=3$, mean $\pm \mathrm{SD})$.

\begin{tabular}{|c|c|c|c|c|c|}
\hline Sr. No. & Nanosponge Type & $\begin{array}{l}\text { Molar Ratio } \\
\beta-C D: \text { DPC }\end{array}$ & $\begin{array}{c}\text { Amount of } \\
\beta-C D(g)\end{array}$ & $\begin{array}{c}\text { Amount of } \\
\text { DPC (g) }\end{array}$ & $\begin{array}{l}\text { Practical Yield } \\
\quad(\mathrm{g}) \pm \mathrm{SD}\end{array}$ \\
\hline 1 & NS2 & $1: 2$ & 4.548 & 1.712 & $3.544 \pm 0.220$ \\
\hline 2 & NS4 & $1: 4$ & 4.548 & 3.424 & $4.559 \pm 0.199$ \\
\hline 3 & NS6 & $1: 6$ & 4.548 & 5.136 & $5.8966 \pm 0.197$ \\
\hline 4 & NS8 & $1: 8$ & 4.548 & 6.848 & $6.434 \pm 0.197$ \\
\hline 5 & NS10 & $1: 10$ & 4.548 & 8.56 & $6.735 \pm 0.296$ * \\
\hline
\end{tabular}

Statistical data analysis from the one-way ANOVA (and nonparametric) Kruskal-Wallis test (practical yield: Kruskal-Wallis statistics: 13.23) was followed by the Dunn's multiple comparison test ${ }^{*} p<0.05$ versus NS2).

The molar ratio ( $\beta-C D$ : DPC) used in nanosponges was found to affect their practical yield. It has been observed that the practical yield increased with an increase in the molar ratio. This may be due to an increase in the number of reactive functional groups at higher concentrations.

\subsection{Solubilization Efficiency of Nanosponges}

The solubilization capacity of $\beta-\mathrm{CD}$ and all the prepared nanosponges for $\mathrm{BO}$ was evaluated and compared with the solubility of the free $\mathrm{BO}$ in double distilled water. All the five types of nanosponges (NS2-NS10) enhanced the solubility of the BO in comparison to free BO, which is shown in Figure 1 (Kruskal-Wallis statistics: 15.10 with $p<0.05)$. Among all, NS4 showed maximum solubilisation efficiency $(1105 \mu \mathrm{g} / \mathrm{mL})$ followed by NS6 $(1030 \mu \mathrm{g} / \mathrm{mL})$ in comparison with free BO $(223.2 \mu \mathrm{g} / \mathrm{mL})$. With plain $\beta-C D$, free BO exhibited solubilisation efficiency $(851.1 \mu \mathrm{g} / \mathrm{mL})$. In this paper, solubilisation efficiency data depicted the superiority of $\beta-C D$ nanosponges over plain $\beta-C D$. The formation of the inclusion complex with the $\mathrm{BO}$ as well as encapsulation in the nanosponge matrix may have resulted in enhanced solubilization of this oil. This observation demonstrated that the encapsulation of BO in nanosponges resulted in the solubility enhancement of this essential oil. However, low solubilization efficiency of NS2, NS8, and NS10 was observed in comparison to plain $\beta$-CD for BO. In NS2, the degree of cross-linking may be low resulting in insufficient nanochannels, which do not have a remarkable impact on the solubility of free BO. However, in NS8 and NS10 formulations, a higher degree of cross-linking created more tortuous and complex nanochannels, which led to the prevention of the entrapment of BO into the NS structures. Anandum and Selvamuthukumar reported that the solubilization of quercetin in milli-Q water was enhanced by 20 times using $\beta-C D$ and DPC as cross linker [19]. 


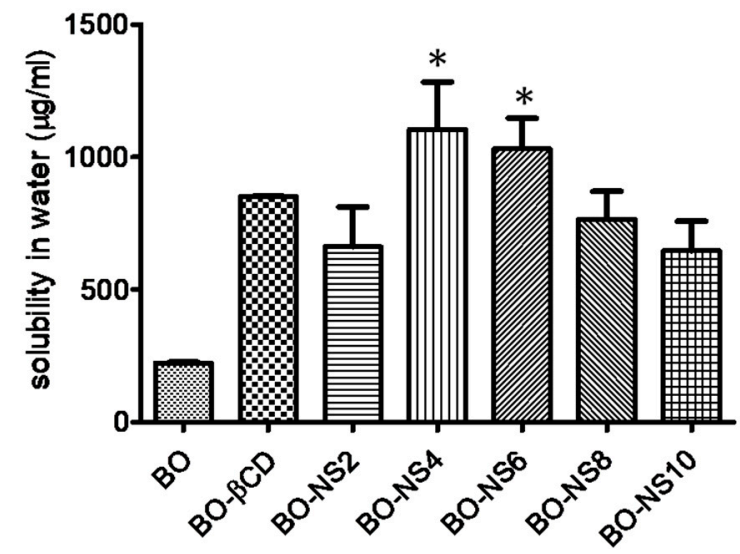

Figure 1. Solubilization of babchi oil (BO) by nanosponges (having different cross-linking density) and $\beta-C D$. Statistical data analysis from the one-way ANOVA (and nonparametric) Kruskal-Wallis test (solubilisation effeciency: Kruskal-Wallis statistics: 15.10) was followed by the Dunn's multiple comparison test $\left({ }^{*} p<0.05\right.$ versus $\left.\mathrm{BO}\right)$.

\subsection{Loading and Encapsulation Efficiency}

$\mathrm{BO}$ was loaded into all five types of nanosponges by using the freeze drying technique. Figure 2 indicates loading efficacy of $\mathrm{BO}$ by NS in different molar ratios. Among the five types of nanosponges, the loading efficiency was observed to be higher in BONS4 (1:4) by as much as $21.47 \% w / w$ followed by BONS6 $(20.44 \%)>$ BONS2 $(19.75 \%)>$ BONS8 $(14.53 \%)>$ BONS10 $(14.23 \%)$. The results revealed that the degree of cross-linking affected the complexation efficiency of nanosponges. It was found that, at the 1:2 molar ratio, the degree of cross-linking may be low, which would result in insufficient nanochannels for the guest complexation. Thus, BO might not be encapsulated in higher amounts. While in BONS6, BONS8 and BONS10, which are the higher amount of the cross-linker resulted in hyper cross-linking of $\beta-C D$, ledto a hindrance in the interaction of $B O$ with $\beta-C D$ cavities. The encapsulation efficiencies of BONS formulations were found to be between $61 \%$ and $93 \%$ (Table 2).

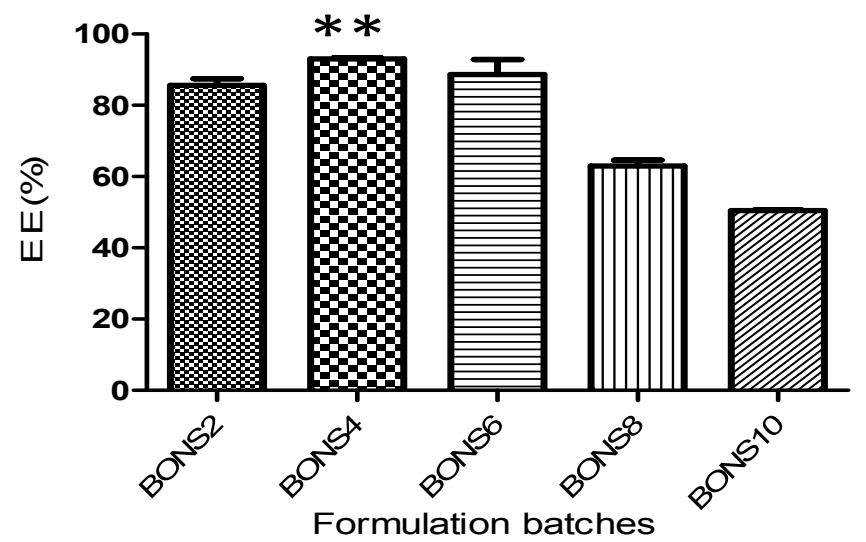

Figure 2. Encapsulation efficiency of the nanosponges (NS2-NS10). Statistical data analysis from a one-way ANOVA (and nonparametric) Kruskal-Wallis test (Encapsulation effeciency: Kruskal-Wallis statistics: 16.97) was followed by a Dunn's multiple comparison test ( ${ }^{* *} p<0.01$ versus BONS10). 
Table 2. Particle sizes, zeta potentials, poly dispersity index, and percentage encapsulation efficiency of the $\mathrm{BO}$ formulations $(n=3$, mean $\pm \mathrm{SD})$.

\begin{tabular}{cccccc}
\hline Sr. No. & Formulation & $\begin{array}{c}\text { Particle Size } \\
(\mathbf{n m} \pm \mathbf{S D})\end{array}$ & $\begin{array}{c}\text { Zeta Potential } \\
(\mathbf{m V} \pm \mathbf{S D})\end{array}$ & $\begin{array}{c}\text { Poly Dispersity } \\
\text { Index } \pm \text { SD }\end{array}$ & $\begin{array}{c}\text { \% Encapsulation } \\
\text { Efficiency } \pm \text { SD }\end{array}$ \\
\hline 1. & BONS1:2 & $261.6 \pm 14.79$ & $-17.8 \pm 2.52$ & $0.312 \pm 0.098$ & $85.61 \pm 1.848$ \\
2. & BONS1:4 & $360.9 \pm 11.55$ & $-16.0 \pm 1.15$ & $0.311 \pm 0.059$ & $93.05 \pm 0.283 *$ \\
3. & BONS1:6 & $234.3 \pm 15.37$ & $-15.5 \pm 1.17$ & $0.188 \pm 0.064$ & $88.61 \pm 4.286$ \\
4. & BONS1:8 & $484.2 \pm 19.89$ & $-15.6 \pm 2.39$ & $0.509 \pm 0.236$ & $62.98 \pm 1.669$ \\
5. & BONS1:10 & $243.3 \pm 12.95$ & $-22.0 \pm 2.47$ & $0.361 \pm 0.113$ & $50.43 \pm 0.173$ \\
\hline
\end{tabular}

Statistical analysis fromthe one-way ANOVA (and nonparametric) Kruskal-Wallis test (encapsulation efficiency: Kruskal-Wallis statistics: 16.97) followed by the Dunn's multiple comparison test. ${ }^{* *} p<0.01$ versus BONS10.

The encapsulation efficiency of entire formulations followed the order: BONS4 $\geq$ BONS6 $\geq$ BONS2 $\geq$ BONS8 $\geq$ BONS10, which is shown in Figure 2. It was found that, for the babchi oil NS, the encapsulation efficiency was highest in BONS4 as much as $93 \%$ while being $61 \%$ in BONS10. The reason for more encapsulation of the $\mathrm{BO}$ in a 1:4 molar ratio may be due to optimum crosslinking involving inclusion and external interactions at the same time, which provides a higher quantity of oil to encapsulate in the nanosponge matrix as well as a cyclodextrin cavity. The effect of $\beta-C D$ and a crosslinker ratio on entrapment efficiency of $\beta$-CD-based nanosponges has been extensively reported [37].

\subsection{Particle Size, Polydispersity Index, and Zeta Potential Determination}

The particle size of the $\mathrm{BO}$ nanosponges ranged from 234 to $484 \mathrm{~nm}$, which is presented in Table 2. All the prepared $\mathrm{BO}$ nanosponges depicted particle size in the nano range $(<1 \mu \mathrm{m})$. Zeta potential of different $\mathrm{BO}$ nanoformulations was also checked as a measure of surface charge. The results of zeta potential obtained are presented in Table 2. High zeta potential shows that the nanosponge would be stable due to a higher magnitude of repulsive forces, which leads to a reduction in their tendency to aggregate. Reduced values of PDI with a narrow range showed that the nanocolloidal suspensions are stable and homogenous in nature. All the prepared nanoformulations were found as fine and free-flowing powders.

Based on the results of the encapsulation and solubilization efficiency, formulation BONS4 was selected for further characterization through FTIR, TGA, XRPD, FE-SEM, and TEM.

\subsection{Fourier Transform Infrared Spectroscopy}

The BO, blank nanosponges, and BONS4 were subjected to FTIR analysis. The FTIR spectrum of the BO showed characteristic absorption bands at around 3434, 2927, 2855, 1744, 1622, 1458, 1376, 1240, 1169 , and $724 \mathrm{~cm}^{-1}$.

Plain NS exhibited a characteristic peak around $1777 \mathrm{~cm}^{-1}$ due to a carbonate bond and $3368 \mathrm{~cm}^{-1}$ due to $\mathrm{O}-\mathrm{H}$ stretching vibration, which confirms the formation of $\mathrm{CD}$-based nanosponges. Additionally, other prominent peaks of NS were found at $2926 \mathrm{~cm}^{-1}$ due to a C-H stretching vibration, $1419 \mathrm{~cm}^{-1}$ due to a $\mathrm{C}-\mathrm{H}$ bending vibration, and $1029 \mathrm{~cm}^{-1}$ due to a $\mathrm{C}-\mathrm{O}$ stretching vibration of primary alcohol. FTIR spectrum of $\beta-C D$ (starting material for NS synthesis) showed no peak around $1700 \mathrm{~cm}^{-1}$. Hence, this ascertains the formation of a carbonate bond after their interaction with cross-linker (DPC) in nanosponges.

The comparison of FTIR spectra of BO, blank NS, and BONS4 evidenced that the characteristic peaks of the $\mathrm{BO}$ were broadened or shifted in nanoformulations, which suggests interactions between oil and nanosponges (Figure 3). 


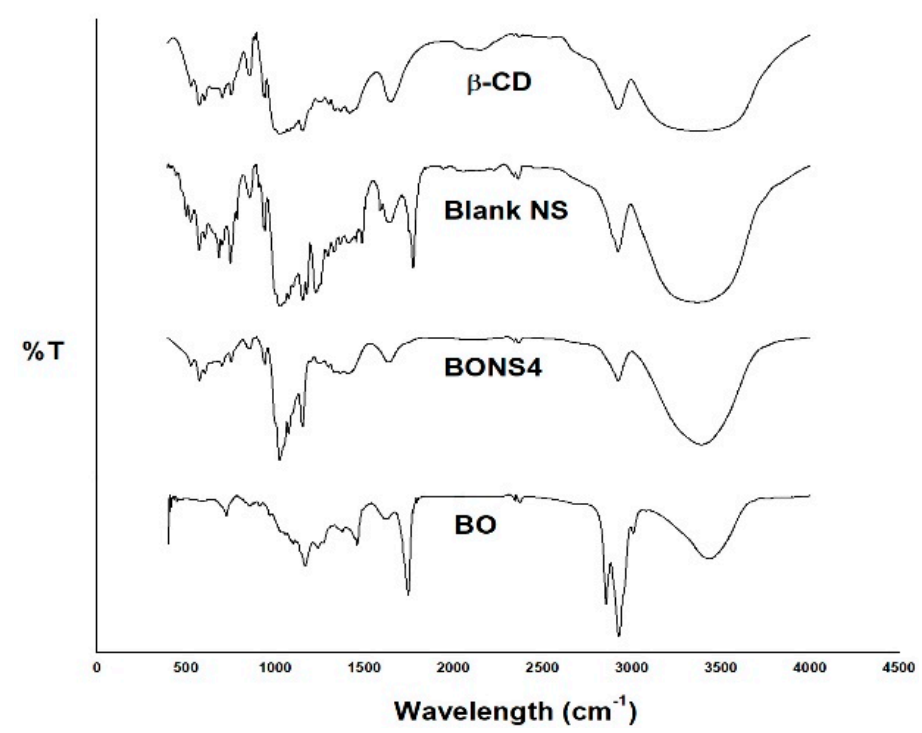

Figure 3. FTIR spectra of BO, $\beta-C D$, blank NS, and BONS4.

\subsection{Thermal Analysis}

Thermo gravimetry analysis is an efficient way to examine alterations in chemical and physical properties of materials. Thermal analysis of $\beta-C D, D P C$, blank NS, and their complexes ascertained not only a presence of an inclusion compound but also a physical mixture of $\beta-C D$ and DPC. Figures 4 and 5 depicted the results of TGA and DTA for $\beta-C D$, DPC, blank NS, and BONS4, respectively.

On one hand, pure $\beta$-CD suffers a first weight loss $(13.8 \%)$ at $112{ }^{\circ} \mathrm{C}$, which is related to the evaporation of water associated with a polymer $(\beta-C D)$. The second zone around $300{ }^{\circ} \mathrm{C}$ to $337^{\circ} \mathrm{C}$ with $53.7 \%$ weight loss can be attributed to the degradation of the $\beta$-CD. The third zone of weight loss $\left(27.9 \%\right.$ to $16.8 \%$ ) from $337^{\circ} \mathrm{C}$ to $438^{\circ} \mathrm{C}$ can be assigned to char degradation. On the other hand, DPC showed weight loss $(96.2 \%)$ at $229^{\circ} \mathrm{C}$, which indicates its complete degradation. In case of the blank nanosponges, the first weight loss $(6.0 \%)$ was observed at $100{ }^{\circ} \mathrm{C}$, which corresponds to water evaporation followed by second weight loss $(35.8 \%)$ at $100^{\circ} \mathrm{C}$ to $218^{\circ} \mathrm{C}$ and finally a third weight loss $(37.0 \%)$ indicated at the $289^{\circ} \mathrm{C}$ to $338^{\circ} \mathrm{C}$. A slight shift of peaks was observed in the case of BO nanosponges, which is observed in the blank nanosponges.

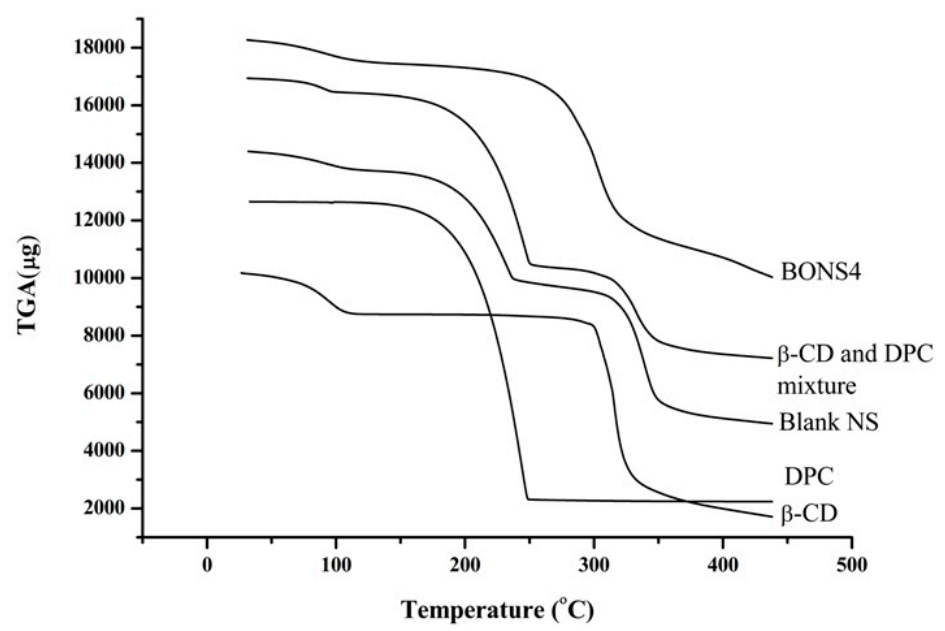

Figure 4. TGA curves of $\beta-C D, D P C$, blank NS, $\beta-C D$ and DPC mixture, and BONS4. 

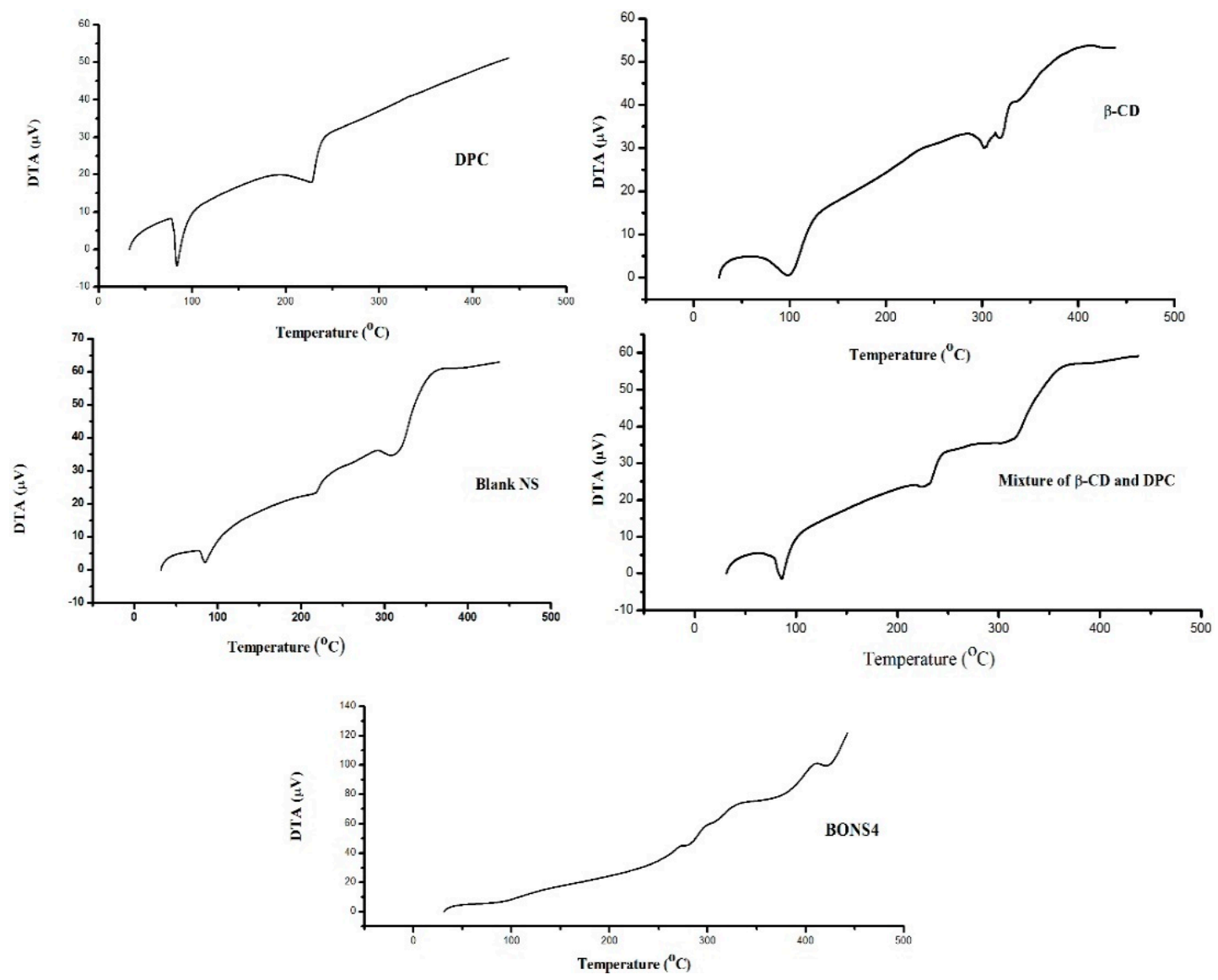

Figure 5. DTA curves of $\beta-C D$, DPC, blank NS, mixture of $\beta-C D$ and DPC, and BONS4.

The TGA curve of the $\beta-C D$ and DPC mixture showed some similarity with blank nanosponges, which ascertained some degree of crosslinking between the polymer and DPC with an increase in temperature. The peak below $100{ }^{\circ} \mathrm{C}$ is associated with a residual moisture in the respective sample. However, for all nanosponges, the maximum degradation processes of their cross linked structures occur at 240 to $300{ }^{\circ} \mathrm{C}$, which indicates good thermal stability. DTG results helped in further strengthening the TGA findings (Table 3).

Table 3. Derivative thermogravimetric analysis of the fabricating materials and nanosponges.

\begin{tabular}{cccc}
\hline \multirow{2}{*}{ Formulating Materials and NS } & \multicolumn{3}{c}{ Derivative Thermo Gravimetric Parameters } \\
\cline { 2 - 4 } & Temperature $\left({ }^{\circ} \mathbf{C}\right)$ & Type of Peak & $\begin{array}{c}\text { Derivative of Thermo } \\
\text { Gravimetry (mg/min) }\end{array}$ \\
\cline { 2 - 4 }$\beta-\mathrm{CD}$ & 98 & Exothermic & 0.30 \\
& 304 & Exothermic & 1.54 \\
DPC & 317 & Exothermic & 3.26 \\
\hline \multirow{2}{*}{$\beta-\mathrm{CD}$ and DPC mixture } & 226 & Sharp exothermic & 2.69 \\
& 80 & Exothermic & 0.14 \\
Blank NS & 231 & Sharp exothermic & 1.57 \\
& 315 & Exothermic & 0.88 \\
\hline \multirow{2}{*}{ BONS4 } & 217 & Exothermic & 0.96 \\
& 323 & Exothermic & 1.57 \\
\hline & 272 & Exothermic & 0.76 \\
& 291 & Exothermic & 1.31 \\
\hline
\end{tabular}


Differential thermal analysis measures the temperature difference between the sample and the reference, which resulted in heat absorption or liberation. As shown in Figure 6, the absence of a characteristic peak in BONS4 indicated the change of the physical state of the components in nanosponges. As indicated in Table 4, these results corroborate the previous findings of thermal analysis of the nanosponges.

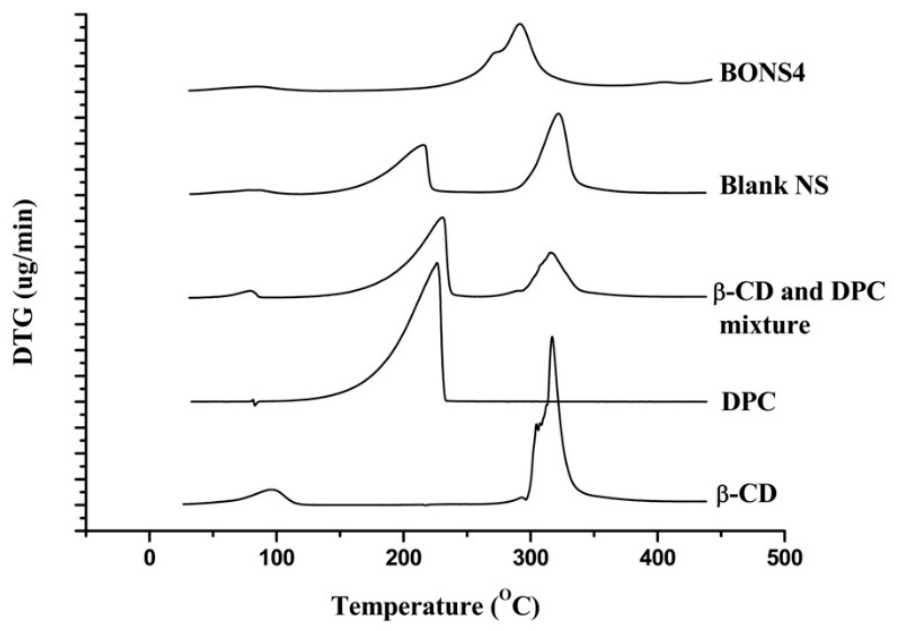

Figure 6. DTG curves of $\beta-C D, D P C, \beta-C D$ and DPC mixture, blank NS, and BONS4.

Table 4. Differential thermal analysis of the fabricating materials and nanosponges.

\begin{tabular}{|c|c|c|c|c|}
\hline \multirow{2}{*}{$\begin{array}{c}\text { Formulating } \\
\text { Materials and NS }\end{array}$} & \multicolumn{4}{|c|}{ Parameters of Differential Thermal Analysis } \\
\hline & $\begin{array}{l}\text { Temperature } \\
\left({ }^{\circ} \mathrm{C}\right)\end{array}$ & Type of Peak & $\begin{array}{l}\text { Change in Enthalpy } \\
(\Delta \mathrm{H}) \mathrm{mJ} / \mathrm{mg}\end{array}$ & $\begin{array}{c}\text { DTA Sensitivity } \\
(\mu \mathrm{V})\end{array}$ \\
\hline \multirow{3}{*}{$\beta-C D$} & 98 & Endothermic & 224 & 0.6 \\
\hline & 302 & Endothermic & 110 & 30 \\
\hline & 320 & Endothermic & 110 & 32.51 \\
\hline \multirow{2}{*}{$\mathrm{DPC}$} & 83 & Endothermic & 96.2 & -4.30 \\
\hline & 228 & Endothermic & 146 & 17.88 \\
\hline \multirow{3}{*}{$\begin{array}{c}\beta-C D \text { and DPC } \\
\text { mixture }\end{array}$} & 86 & Endothermic & 108 & -1.50 \\
\hline & 231 & Endothermic & 49.5 & 24.3 \\
\hline & 317 & Endothermic & 160 & 37 \\
\hline \multirow{3}{*}{ Blank NS } & 85 & Endothermic & 36.6 & 2.3 \\
\hline & 218 & Endothermic & 35.3 & 23.4 \\
\hline & 314 & Endothermic & 189 & 35.3 \\
\hline BONS4 & - & - & - & - \\
\hline
\end{tabular}

\subsection{X-Ray Powder Diffraction}

The diffraction pattern of blank nanosponges and BONS4 has been shown in Figure 7. A significant difference between their diffractogram exists, i.e., reduction in the intensity of peaks was observed. Hence, the XRPD studies indicated that, after freeze drying (BONS4), a fluffy powder was obtained with a highly porous structure losing its crystallinity. The characteristic peaks of the blank nanosponges were observed at $10.53^{\circ}, 12.37^{\circ}, 15.14^{\circ}, 16.99^{\circ}, 18.60^{\circ}, 19.29^{\circ}, 20.92^{\circ}, 22.52^{\circ}, 24.15^{\circ}, 25.30^{\circ}, 26.90^{\circ}$, $28.52^{\circ}, 31.05^{\circ}, 34.75^{\circ}, 36.60^{\circ}$, and $39.83^{\circ}(2 \theta)$, which is indicated in Figure 7 . The intensity of these peaks were weakened in the BO loaded nanosponges (Figure 7), which depicts a reduction of the crystallinity of the CD nanosponges after encapsulation of $\mathrm{BO}$. 


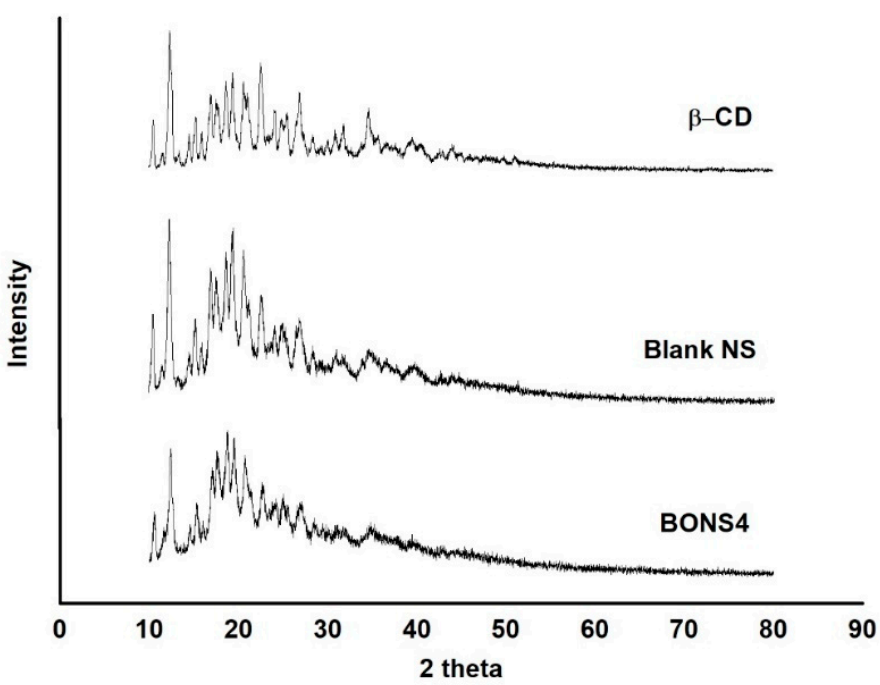

Figure 7. XRPD patterns of $\beta-C D$, blank NS, and BONS4.

\subsection{Surface Morphology}

The surface topography of the prepared nanosponges was also studied using scanning electron microscopy. As observed in FE-SEM images (Figure 8), cyclodextrin nanosponges showed crystalline morphologies. Additionally, the morphology of the selected BO nanosponges (BONS4) and blank nanosponges was studied by using transmission electron microscopy. Using TEM, a single crystal of a nanosponge can be focused by elucidating its definite crystalline geometry. As shown in representative TEM photographs (Figure 9), the dimensions of the crystal lattice agreed well with XRPD findings. The morphological characterization by this microscopy showed that the nanosponges prepared by a melt method, possesses a uniform size distribution, crystallinity, and a porous nature. Furthermore, lattice planes lying straight across the nanosponges indicated that the obtained nanosponges possess a high degree of crystallinity.

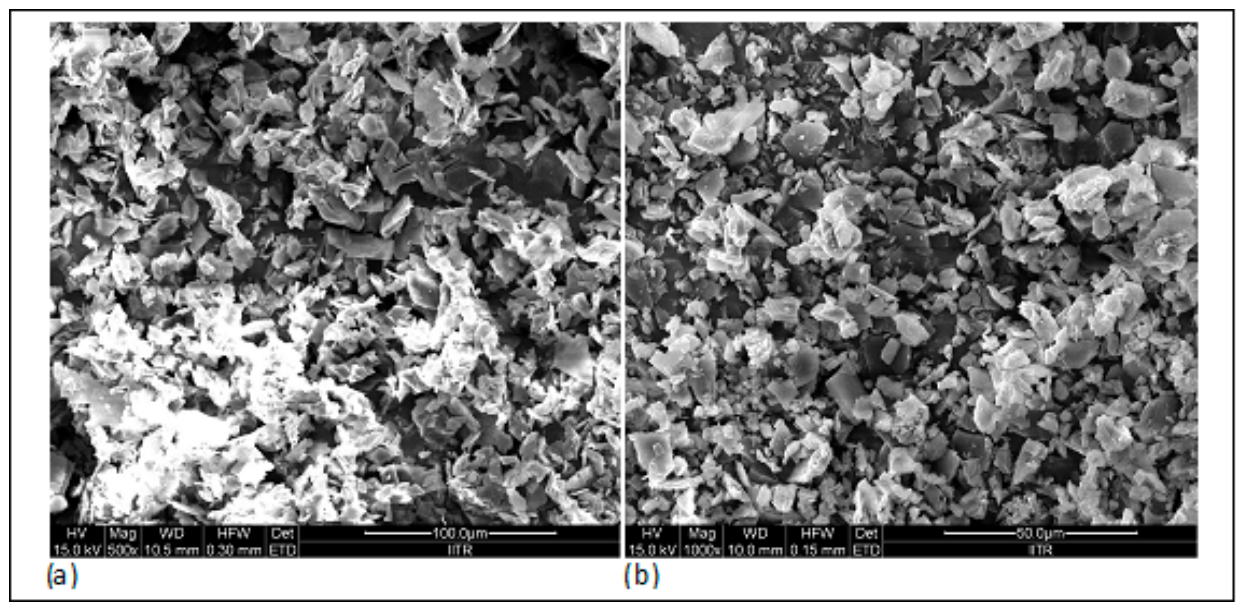

Figure 8. Field emission scanning electron microscopy: (a) plain NS and (b) BONS4. 

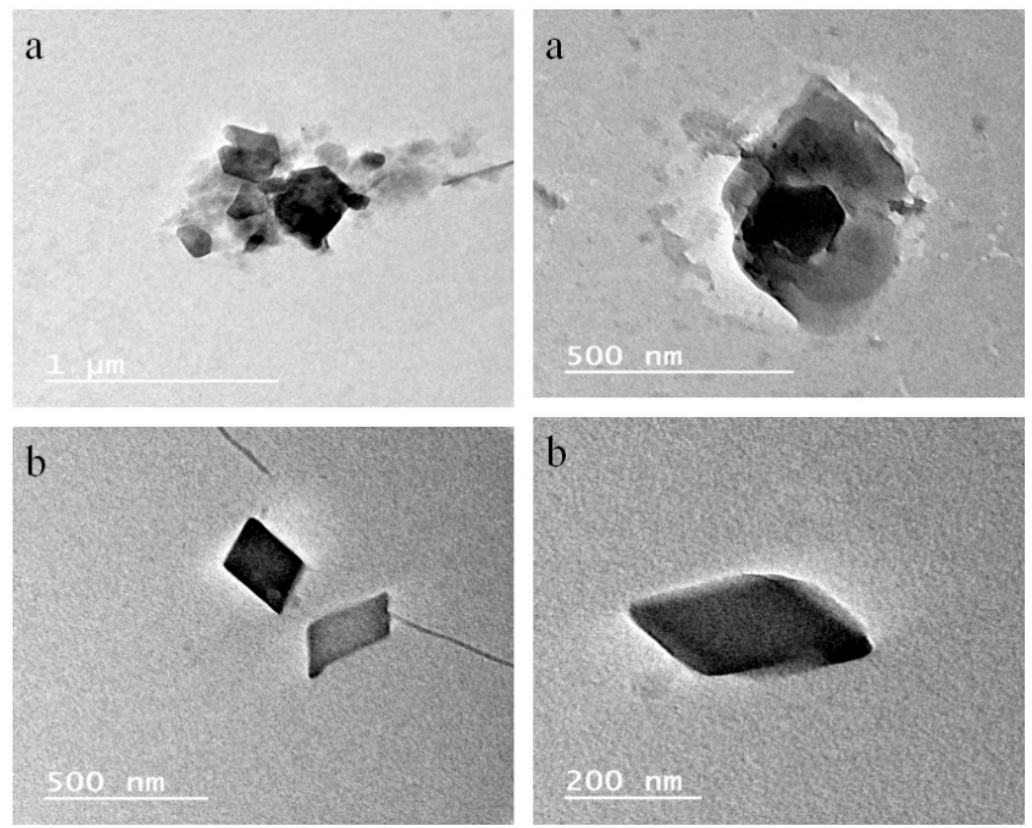

Figure 9. TEM images of (a) blank nanosponges and (b) BONS4.

\subsection{Cytotoxicity Studies against HaCaT Cell Lines}

Most of the essential oils have been reported to produce toxicity or skin irritation in spite of their good topical advantages. To compare the cytotoxicity of plain BO and BONS4, the dose response curve was established. The results indicated that cytotoxicity of the BONS was slightly less than that of BO. Hence, in order to explore the potential benefits of $\mathrm{BO}$ loaded nanosponges on human keratinocytes, the cytotoxicity of $\mathrm{BO}$ and $\mathrm{BO}$ loaded nanosponges were studied using the MTT assay and the results of human skin cells treated with different concentrations are presented in Table 5.

Table 5. Effect of BO and BONS on the viability of HaCaT cells as a function of drug concentration at $24 \mathrm{~h}$.

\begin{tabular}{cccc}
\hline Sample & Concentration $\mu \mathrm{g} / \mathrm{mL}$ & $\begin{array}{c}\text { \% Inhibition } \pm \text { Standard } \\
\text { Deviation }(\boldsymbol{n}=\mathbf{3})\end{array}$ & IC50 \\
\hline Control & 0 & $0.00 \pm 0.00$ & \\
& 10 & $4.41 \pm 1.21$ & $172.3 \mu \mathrm{g} / \mathrm{mL}$ \\
Babchi oil (BO) & 20 & $7.48 \pm 1.47$ & \\
& 40 & $16.84 \pm 1.40$ & \\
& 80 & $23.45 \pm 1.20$ & \\
& 160 & $38.61 \pm 2.16$ & \\
Babchi oil loaded & 320 & $51.16 \pm 2.23$ & \\
nanosponges (BONS) & 10 & $4.26 \pm 1.96$ & \\
& 20 & $9.60 \pm 1.63$ & \\
& 40 & $16.39 \pm 1.74$ & \\
& 80 & $25.86 \pm 2.29$ & \\
& 160 & $68.73 \pm 2.09$ & \\
\hline
\end{tabular}

Both of these samples resulted in dose-dependent reductions in cellular viability. Furthermore, the MTT assay showed that the treatment of these cells with BO loaded nanosponges at $320 \mu \mathrm{g} / \mathrm{mL}$ resulted in a cytotoxic effect with IC50 value $191.4 \mu \mathrm{g} / \mathrm{mL}$ and plain BO with an IC50 value of 172.3 $\mu \mathrm{g} / \mathrm{mL}$. However, there is no significant difference between the cytotoxicity caused by BO and BONS, which indicates that a sufficient quantity of the drug is released from nanosponges to cause cell toxicity. 
Hence, the results of the MTT assay indicated that the developed nanoformulation is safer on human skin cells in comparison to babchi essential oil (Table 5).

\subsection{Photodegradation Study}

BO gets absorbed in the UV region that exhibits a peak around $265 \mathrm{~nm}$. The intensity of this peak was found to be diminished upon UVA illumination, which ascertains photolysis of BO constituents.

With the objective of evaluating the protective phenomenon of nanosponges on the photo degradation of the $\mathrm{BO}$ constituents, the photo degradation kinetics of this oil and oil-loaded nanosponges was also compared $[18,38,39]$.

The BO concentration was plotted as a function of irradiation time to analyze the photo degradation kinetics. The obtained exponential asymptotic curve of the degraded $\mathrm{BO}$ upon $\mathrm{BO}$ irradiation followed first order kinetics. The following logarithmic equation was used for the calculation of the slope of the obtained curves.

$$
\ln C_{t} / C_{0}=-k \times t
$$

where $C_{0}$ is the initial concentration of $\mathrm{BO}$ and $C_{t}$ represents its residual concentration at time $t$. The rate constant data can be calculated using the linear dependence of $\ln C_{t} / C_{0}$ vs. time. The $k$ values were calculated using the pseudo-first order model fitting (Table 6).

Table 6. Correlation coefficient $\left(r^{2}\right)$ and rate constant $(k)$ of BO and BONS4 photo degradation under UVA irradiation.

\begin{tabular}{|c|c|c|c|}
\hline Sr. No. & Oil and Its Formulation & Correlation Coefficient $\left(r^{2}\right)$ & Rate Constant $(k)\left(1 \times 10^{-3} \min ^{-1}\right)$ \\
\hline 1. & $\mathrm{BO}$ & $0.953 \pm 0.14$ & $6.909 \pm 0.63$ \\
\hline 2. & BONS4 & $0.405 \pm 0.10$ & $2.303 \pm 0.47$ \\
\hline
\end{tabular}

A comparison of rate constants of photo degradation exhibited by BO $\left(6.909 \times 10^{-3} \pm 0.63 \mathrm{~min}^{-1}\right)$ and $\mathrm{BO}$ loaded nanosponges $\left(2.303 \times 10^{-3} \pm 0.47 \mathrm{~min}^{-1}\right)$ advocated that $\mathrm{BO}$ loaded nanosponges are capable of slowing the photo oxidation process due to the physical barrier provided by nanosponges against UV-induced oxidation of BO.

\subsection{Antibacterial Activity}

BO loaded nanosponges showed a clear inhibitory effect against P. aeruginosa, E. coli, and S. aureus. Yet, babchi essential oils also exhibited an inhibitory effect. The antibacterial effect was remarkably improved for BO-loaded nanosponges. The zone of growth inhibition for $\mathrm{BO}$ were as follows: $12.33 \pm 2.5 \mathrm{~mm}$ for $S$. aureus, $12 \pm 2.4 \mathrm{~mm}$ for E. coli, $12.33 \pm 2.3 \mathrm{~mm}$ for P. aeruginosa while, in BONS dispersion, it was $16.00 \pm 2.64 \mathrm{~mm}$ for $S$. aureus, $17 \pm 3.00 \mathrm{~mm}$ for E. coli, and $16 \pm 0.00 \mathrm{~mm}$ for P. aeruginosa (Figure 10). The positive control streptomycin $(10 \mu \mathrm{g} / \mathrm{mL})$ produced a comparable zone of growth inhibition against $S$. Aureus $(10.00 \pm 1.00 \mathrm{~mm})$, E. coli $(16 \pm 1.00 \mathrm{~mm}$ for), and P. aeruginosa $(15.33 \pm 2.51 \mathrm{~mm})$ while negative control (blank nanosponge dispersion) plates did not show growth inhibition of the above mentioned bacteria. The restraining antibacterial effects of BO against P. aeruginosa, E. coli, and S. aureus can be assigned due to water insolubility and the volatile nature of oil. As observed from solubility studies, the entrapment of the BO in cyclodextrin nanosponges potentially improved the water solubility, which might have resulted in the enhancement of antibacterial activity. 


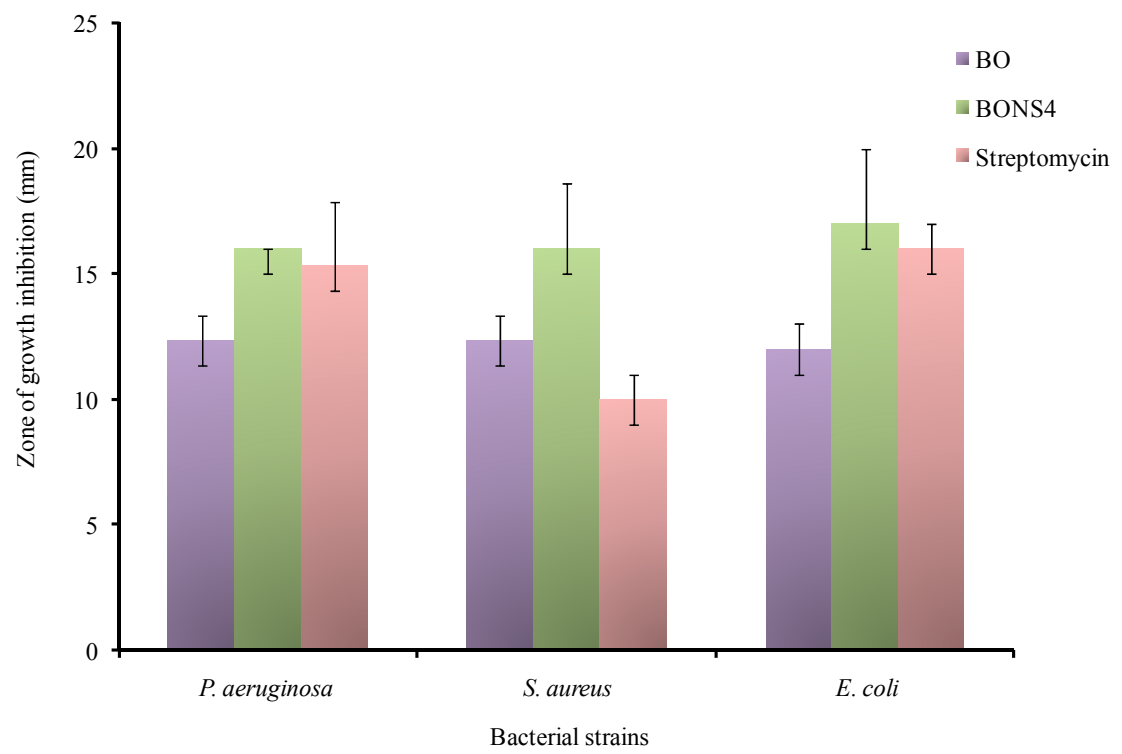

Figure 10. Antibacterial activities of Psoralea corylifolia seed oil. BO-Babchi oil and BONS4-Optimized babchi oil loaded nanosponges.

\section{Conclusions}

The present study reports on the encapsulation of babchi essential oil in $\beta$-cyclodextrin nanosponges. First, GCMS analysis of BO was performed in order to identify the compounds present in this oil. A solubilization efficiency assessment showed all five types of fabricated nanosponges, which enhanced the solubility of $\mathrm{BO}$ in comparison to free $\mathrm{BO}$. The $\mathrm{BO}$ was efficiently loaded in diphenylcarbonate cross-linked $\beta$-cyclodextrin nanosponges using a freeze drying technique. The results of the encapsulation efficiency implies that an optimum ratio of the polymer to the cross linker in BO nanosponges is 1:4 (molar ratio) and the product processed from this molar ratio can help deliver a therapeutically effective dose. Spectral characterization data revealed the formation of stable inclusion complexes in nanosponges. The prepared nanosponges displayed good thermal stability. Cytotoxicity studies explored the enhancement in the therapeutic response that will retard the overall drug consumption and dose and will minimize systemic side effects due to drug localization at the target site. On the basis of calculated kinetic parameters, the nanosponge complexation minimizes the UV photodegradation. The fabricated optimized formulation was also found active on bacteria such as P. aeruginosa, E. coli, and S. aureus when compared with pure essential oil. Furthermore, research on the pharmacological evaluation of $\mathrm{BO}$ nanosponges is in progress. It will be helpful to explain the potential of $\mathrm{BO}$ nanosponges for therapeutic applications.

Author Contributions: Conceptualization, R.R.; Methodology, S.K.; Validation, S.K.; Formal Analysis, S.K. and P.; Investigation, R.R.; Resources, S.K. and P.; Writing-Original Draft Preparation, S.K.; Writing-Review \& Editing, S.K., F.T. and P.; Visualization, R.R. and F.T.; Supervision, R.R.; Project Administration, R.R.; Funding Acquisition, F.T.

Funding: This research received no external funding.

Acknowledgments: The researchers would like to acknowledge the coordinator, DST-FIST, Department of Pharmaceutical Sciences, Guru Jambheshwar, Univeristy of Science and Technology, Hisar for carrying out the zeta potential and particles size analysis. Pukhraj Herbals, Mandsaur, and Jay Chem Marketing, Mumbai are also acknowledged for providing a gift sample of babchi oil and $\beta$-cyclodextrin.

Conflicts of Interest: Authors declare no conflict of interest. 


\section{References}

1. Rossi, S.; Ferrari, F.; Bonferoni, M.C.; Caramella, C. Characterization of chitosan hydrochloride-mucin interaction by means of viscosimetric and turbidimetric measurements. Eur. J. Pharm. Sci. 2000, 10, $251-257$. [CrossRef]

2. Munin, A.; Edwards-Lévy, F. Encapsulation of natural polyphenolic compounds; a review. Pharmaceutics 2011, 3, 793-829. [CrossRef] [PubMed]

3. Wadhwa, G.; Kumar, S.; Chhabra, L.; Mahant, S.; Rao, R. Essential oil-cyclodextrin complexes: An updated review. J. Incl. Phenom. Macrocycl. Chem. 2017, 89, 39-58. [CrossRef]

4. Szejtli, J. Cyclodextrin in drug formulations Part, I. Pharm. Technol. Int. 1991, 3, 15-22.

5. Cavalli, R.; Trotta, F.; Tumiatti, W. Cyclodextrin-based nanosponges for drug delivery. J. Incl. Phenom. Macrocycl. Chem. 2006, 56, 209-213. [CrossRef]

6. Trotta, F.; Zanetti, M.; Cavalli, R. Cyclodextrin-based nanosponges as drug carriers. Beilstein J. Org. Chem. 2012, 8, 2091-2099. [CrossRef] [PubMed]

7. Trotta, F.; Dianzani, C.; Caldera, F.; Mognetti, B.; Cavalli, R. The application of nanosponges to cancer drug delivery. Expert Opin. Drug Deliv. 2014, 11, 931-941. [CrossRef] [PubMed]

8. Swaminathan, S.; Cavalli, R.; Trotta, F. Cyclodextrin-based nanosponges: A versatile platform for cancer nanotherapeutics development. Wiley Interdiscip. Rev. Nanomed. Nanobiotechnol. 2016, 8, 579-601. [CrossRef] [PubMed]

9. Deshmukh, K.; Tanwar, Y.S.; Shende, P.; Cavalli, R. Biomimetic estimation of glucose using non-molecular and molecular imprinted polymer nanosponges. Int. J. Pharm. 2015, 494, 244-248. [CrossRef] [PubMed]

10. Turek, C.; Stintzing, F.C. Stability of essential oils: A review. Compr. Rev. Food Sci. Food Saf. 2013, 12, 40-53. [CrossRef]

11. Chopra, B.; Dhingra, A.K.; Dhar, K.L. Psoralea corylifolia, L. (Buguchi)_Folklore to modern evidence: Review. Fitoterapia 2013, 90, 44-56. [CrossRef] [PubMed]

12. Kumar, S.; Rao, R. Psoralen: A promising boon in topical manifestations. IJP 2016, 3, 375-383.

13. Chang, L. Psoriasis Phototherapy: UVA Beats UVB. WebMD Medical News Daniel De Noon. 2006. Available online: https:/ / www.webmd.com/skin-problems-and-treatments/psoriasis/news/20060718/psoriasisphototherapy-uva-beats-uvb (accessed on 21 August 2018).

14. Musthaba, S.M.; Baboota, S.; Ahmed, S.; Ahuja, A.; Ali, J. Status of novel drug delivery technology for phytotherapeutics. Expert Opin. Drug Deliv. 2009, 6, 625-637. [CrossRef] [PubMed]

15. Pradhan, M.; Singh, D.; Singh, M.R. Novel colloidal carriers for psoriasis: Current issues, mechanistic insight and novel delivery approaches. J. Control. Release 2013, 170, 380-395. [CrossRef] [PubMed]

16. Mognetti, B.; Barberis, A.; Marino, S.; Berta, G.; De Francia, S.; Trotta, F.; Cavalli, R. In vitro enhancement of anticancer activity of paclitaxel by a Cremophor free cyclodextrin-based nanosponge formulation. J. Incl. Phenom. Macrocycl. Chem. 2012, 74, 201-210. [CrossRef]

17. Tejashri, G.; Amrita, B.; Darshana, J. Cyclodextrin based nanosponges for pharmaceutical use: A review. Acta Pharm. 2013, 63, 335-358. [CrossRef] [PubMed]

18. Sapino, S.; Carlotti, M.E.; Cavalli, R.; Ugazio, E.; Berlier, G.; Gastaldi, L.; Morel, S. Photochemical and antioxidant properties of gamma-oryzanol in beta-cyclodextrin-based nanosponges. J. Incl. Phenom. Macrocycl. Chem. 2013, 75, 69-76. [CrossRef]

19. Anandam, S.; Selvamuthukumar, S. Fabrication of cyclodextrin nanosponges for quercetin delivery: Physicochemical characterization, photostability, and antioxidant effects. J. Mater. Sci. 2014, 49, 8140-8153. [CrossRef]

20. Ansari, K.A.; Vavia, P.R.; Trotta, F.; Cavalli, R. Cyclodextrin-based nanosponges for delivery of resveratrol: In vitro characterisation, stability, cytotoxicity and permeation study. AAPS PharmSciTech 2011, 12, 279-286. [CrossRef] [PubMed]

21. Darandale, S.S.; Vavia, P.R. Cyclodextrin-based nanosponges of curcumin: Formulation and physicochemical characterization. J. Incl. Phenom. Macrocycl. Chem. 2013, 75, 315-322. [CrossRef]

22. Ramírez-Ambrosi, M.; Caldera, F.; Trotta, F.; Berrueta, L.Á.; Gallo, B. Encapsulation of apple polyphenols in $\beta$-CD nanosponges. J. Incl. Phenom. Macrocycl. Chem. 2014, 80, 85-92. [CrossRef]

23. Rao, M.; Bajaj, A.; Khole, I.; Munjapara, G.; Trotta, F. In vitro and in vivo evaluation of $\beta$-cyclodextrin-based nanosponges of telmisartan. J. Incl. Phenom. Macrocycl. Chem. 2013, 77, 135-145. [CrossRef] 
24. Rao, M.R.; Shirsath, C. Enhancement of Bioavailability of Non-nucleoside Reverse Transciptase Inhibitor Using Nanosponges. AAPS PharmSciTech 2017, 18, 1728-1738. [CrossRef] [PubMed]

25. Swaminathan, S.; Vavia, P.R.; Trotta, F.; Cavalli, R.; Tumbiolo, S.; Bertinetti, L.; Coluccia, S. Structural evidence of differential forms of nanosponges of beta-cyclodextrin and its effect on solubilization of a model drug. J. Incl. Phenom. Macrocycl. Chem. 2013, 76, 201-211. [CrossRef]

26. Boukamp, P.; Petrussevska, R.T.; Breitkreutz, D.; Hornung, J.; Markham, A.; Fusenig, N.E. Normal keratinization in a spontaneously immortalized aneuploid human keratinocyte cell line. J. Cell Biol. 1988, 106, 761-771. [CrossRef] [PubMed]

27. Schürer, N.; Köhne, A.; Schliep, V.; Barlag, K.; Goerz, G. Lipid composition and synthesis of HaCaT cells, an immortalized human keratinocyte line, in comparison with normal human adult keratinocytes. Exp. Dermatol. 1993, 2, 179-185. [CrossRef] [PubMed]

28. Borate, A.; Khambhapati, A.; Udgire, M.; Paul, D.; Mathur, S. Preliminary phytochemical studies and evaluation of antibacterial activity of Psoraleacorylifolia seed extract. IJMRR 2014, 2, 95-101.

29. Loftsson, T.; Brewster, M. Pharmaceutical applications of cyclodextrins: Drug solubilisation and stabilization. J. Pharm. Pharmacol. 1996, 85, 1017-1025. [CrossRef] [PubMed]

30. Trotta, F.; Tumiatti, V.; Cavalli, R.; Roggero, C.; Mognetti, B.; Berta, G. Cyclodextrin-Based Nanosponges as a Vehicle for Antitumoral Drugs. Patent No. WO2009/003656 A1, 8 January 2009.

31. Available online: http://www.inchem.org/documents/sids/sids/102090.pdf (accessed on 7 December 2016).

32. Sharma, R.; Pathak, K. Polymeric nanosponges as an alternative carrier for improved retention of econazole nitrate onto the skin through topical hydrogel formulation. Pharm. Dev. Technol. 2011, 16, 367-376. [CrossRef] [PubMed]

33. Anandam, S.; Selvamuthukumar, S. Optimization of microwave-assisted synthesis of cyclodextrin nanosponges using response surface methodology. J. Porous Mater. 2014, 21, 1015-1023. [CrossRef]

34. Ferro, M.; Castiglione, F.; Punta, C.; Melone, L.; Panzeri, W.; Rossi, B.; Trotta, F.; Mele, A. Anomalous diffusion of Ibuprofen in cyclodextrin nanosponge hydrogels: An HRMAS NMR study. Beilstein J. Org. Chem. 2014, 10, 2715-2723. [CrossRef] [PubMed]

35. Selvamuthukumar, S.; Anandam, S.; Krishnamoorthy, K.; Rajappan, M. Nanosponges: A novel class of drug delivery system-review. J. Pharm. Pharm. Sci. 2012, 15, 103-111.

36. Aldawsari, H.M.; Badr-Eldin, S.M.; Labib, G.S.; El-Kamel, A.H. Design and formulation of a topical hydrogel integrating lemongrass-loaded nanosponges with an enhanced antifungal effect: In vitro/in vivo evaluation. Int. J. Nanomed. 2015, 10, 893-902.

37. Olteanu, A.A.; Aramă, C.C.; Radu, C.; Mihăescu, C.; Monciu, C.M. Effect of $\beta$-cyclodextrins based nanosponges on the solubility of lipophilic pharmacological active substances (repaglinide). J. Incl. Phenom. Macrocycl. Chem. 2014, 80, 17-24. [CrossRef]

38. Carlotti, M.E.; Sapino, S.; Vione, D.; Pelizzetti, E.; Trotta, M. Photostability of Trolox in Water/Ethanol, Water, and Oramix CG 110 in the Absence and in the Presence of $\mathrm{TiO}_{2}$. J. Dispers. Sci. Technol. 2004, 25, 193-207. [CrossRef]

39. Carlotti, M.E.; Sapino, S.; Vione, D.; Minero, C.; Peira, E.; Trotta, M. Study on the photodegradation of salicylic acid in different vehicles in the absence and in the presence of $\mathrm{TiO}_{2}$. J. Dispers. Sci. Technol. 2007, 28, 805-818. [CrossRef]

(C) 2018 by the authors. Licensee MDPI, Basel, Switzerland. This article is an open access article distributed under the terms and conditions of the Creative Commons Attribution (CC BY) license (http://creativecommons.org/licenses/by/4.0/). 